\title{
Differential effects of short-chain fatty acids and iron on expression of iha in Shiga-toxigenic Escherichia coli
}

Correspondence

Adrienne W. Paton

adrienne.paton@adelaide.edu.au

Received 18 March 2009

Revised 6 August 2009

Accepted 9 August 2009
Sylvia Herold, James C. Paton, Potjanee Srimanote and Adrienne W. Paton

Research Centre for Infectious Diseases, School of Molecular and Biomedical Science, University of Adelaide, South Australia, 5005, Australia

\begin{abstract}
Shiga-toxigenic Escherichia coli (STEC) colonizing the bowel are exposed to a variety of shortchain fatty acids (SCFAs), including acetate, propionate and butyrate, produced by gut microflora. However, the total concentrations and relative amounts of SCFAs in the lumen vary with intestinal niche. Here we report that conditions simulating SCFA concentrations present in the human gut trigger expression of the iha gene, which encodes an adherence-conferring outer-membrane protein of pathogenic E. coli. We show that growth under conditions simulating colonic, but not ileal, SCFA concentrations increases iha expression in three tested STEC strains, with the strongest expression detected in LEE-negative STEC 0113:H21 strain 98NK2. Expression of iha is known to be subject to Fur-mediated iron repression in 0157:H7 STEC, and the same occurs in 98NK2. However, exogenous iron did not repress iha expression in the presence of colonic SCFAs in either 98NK2 or the 0157:H7 strain EDL933. Moreover, exposure to the iron chelator 2,2 '-dipyridyl caused no further enhancement of iha expression over that induced by colonic SCFAs. These findings indicate that SCFAs regulate iha expression in STEC independently of iron. Increased expression of iha under colonic but not ileal SCFA conditions possibly may contribute to preferential colonization of the human colon by STEC.
\end{abstract}

\section{INTRODUCTION}

Shiga-toxigenic Escherichia coli (STEC) cause food-borne infections in humans, commencing with watery or bloody diarrhoea that can progress to haemorrhagic colitis and the life-threatening haemolytic uraemic syndrome (HUS) (Karmali, 1989; Nataro \& Kaper, 1998; Paton \& Paton, 1998). STEC are classified into two major groups in accordance with the presence of the locus of enterocyte effacement (LEE). LEE-positive strains have the ability to produce attaching and effacing lesions on the intestinal epithelium, characterized by intimate attachment of the bacteria to the epithelial cell surface, rearrangement of the cell cytoskeleton and effacement of the epithelial microvilli, as reviewed by Frankel et al. (1998). However, the presence of LEE is not essential for pathogenesis, as both sporadic cases and even outbreaks of HUS can be caused by LEEnegative STEC (Karmali et al., 1985; Paton et al., 1999). Thus, alternative accessory virulence factors, in particular adherence-mediating molecules, may also play a role in pathogenesis. Among STEC a range of novel adhesins have been identified, including the chromosomally encoded adherence-conferring protein Iha, a homologue of Vibrio

Abbreviations: LEE, locus of enterocyte effacement; HUS, haemolytic uraemic syndrome; SCFA, short-chain fatty acid; STEC, Shiga-toxigenic Escherichia coli; UPEC, uropathogenic E. coli. cholera IrgA (Tarr et al., 2000). Iha was first characterized in E. coli O157:H7, but it is distributed widely among LEEnegative and LEE-positive STEC, as well as in uropathogenic E. coli (UPEC) (Johnson et al., 2000; Tarr et al., 2000). Tarr et al. (2000) reported that an iha deletion mutant of O157:H7 STEC was impaired in adherence to HeLa cells, although the difference did not reach statistical significance. Nevertheless, there was a highly significant increase in adherence to both HeLa and MDBK cells when iha was expressed from a plasmid in a non-piliated recombinant E. coli host. The high prevalence $(91 \%)$ of iha in STEC belonging to different seropathotypes and the presence of multiple iha copies in some strains point to the potential importance of this novel adhesin (Tarr et al., 2000; Toma et al., 2004). In the UPEC strain CFT073, iha functions as a urovirulence factor, by contributing to colonization in a mouse urinary tract infection model (Johnson et al., 2005). Furthermore, Iha from UPEC strain UCB34 functions as a catecholate siderophore receptor in E. coli K-12. The capacity of Iha to transport siderophores is TonB-dependent, whereby the protein complex TonB/ ExbB/ExbD provides the energy required for active transport (Leveille et al., 2006; Postle \& Kadner, 2003). Additionally, iha expression is regulated by the ferricuptake regulator protein Fur (Rashid et al., 2006b). In the presence of iron, dimerized Fur binds via a 
sequence-specific protein-DNA interaction to iha promoter regions and represses iha transcription. Under ironlimiting conditions, Fur is unable to interact with the DNA and as a consequence, iha transcription is de-repressed (Leveille et al., 2006; Rashid et al., 2006b). Free iron levels are typically low at mucosal surfaces, due to binding by host lactoferrin, and so induction of iron-scavenging mechanisms is an important bacterial in vivo survival strategy. However, Fe levels need to be carefully regulated to avoid oxidative stress induced by the Fenton reaction (Touati, 2000). Iron is an important environmental cue, and iron-limiting conditions induce virulence-related genes in a number of pathogens (Litwin \& Calderwood, 1993; Touati, 2000).

STEC efficiently colonize the human gut, and, although direct evidence is limited, the colon is believed to be the primary site of such colonization. The gastrointestinal tract is a complex microenvironment containing, among other substances, a variety of short-chain fatty acids (SCFAs), which are a major metabolic product of probiotic bacteria. The three principal organic acids present in the intestine are acetate, propionate and butyrate, but the composition and concentration varies between the ileum and colon (Cummings et al., 1987; Cummings \& Macfarlane, 1991; Macfarlane et al., 1992; Salminen et al., 1998). Diet also affects relative SCFA composition; for example, the main product of starch fermentation is butyrate, whereas pectin fermentation yields more acetate (Cummings \& Macfarlane, 1991; Gilbert et al., 2005). The total concentration of SCFAs in the gut is also affected by time after ingestion, as SCFAs are absorbed rapidly (Salminen et al., 1998). Nevertheless, Cummings et al. (1987) have estimated concentrations of SCFAs at $13 \pm 6 \mathrm{mmol} \mathrm{kg}^{-1}$ in the terminal ileum, $80 \pm 11 \mathrm{mmol} \mathrm{kg}^{-1}$ in the caecum and $131 \pm 9 \mathrm{mmol} \mathrm{kg}^{-1}$ in the descending colon. Another study estimated concentrations of SCFAs at approximately $97 \mathrm{mmol} \mathrm{kg}{ }^{-1}$ in the descending colon and $198 \mathrm{mmol}$ $\mathrm{kg}^{-1}$ in the caecum (Macfarlane et al., 1992). Furthermore, in the food industry fatty acids are widely used as preservatives at concentrations ranging from 1 to $4 \%$ (reviewed by Erickson \& Doyle, 2007). STEC infections result from consumption of contaminated food products and so pathogens may be exposed to SCFAs during food processing, as well as during colonization of the human gut. A number of studies have shown that SCFAs can act as environmental cues, triggering alterations in gene expression, as well as directly inhibiting the growth of pathogenic bacteria (Arnold et al., 2001; Gantois et al., 2006; Kwon \& Ricke, 1998; Lawhon et al., 2002; Shin et al., 2002). Variations in SCFA composition in different regions of the gastrointestinal tract (Cummings et al., 1987, 2001; Cummings \& Macfarlane, 1991; Lawhon et al., 2002; Macfarlane et al., 1992) may also enable differential expression of virulence factors in specific host microenvironments. Here we investigate the effects of SCFAs, simulating concentrations in the colon and ileum, on expression of iha by the hyper-virulent LEE-negative STEC
O113:H21 strain 98NK2 and LEE-positive STEC O157:H7 strains EDL933 and 86-24.

\section{METHODS}

Bacterial strains and plasmids. The E. coli strains and plasmids used in this study are listed in Table 1 . Cells were routinely grown in Luria-Bertani (LB) medium with or without $1.5 \%$ Bacto agar. As recovery medium for transformants, SOC medium $\left(20\right.$ g tryptone $\mathrm{l}^{-1}$, 5 g yeast extract $1^{-1}, 20 \mathrm{mM}$ glucose, $8.6 \mathrm{mM} \mathrm{NaCl}, 2.5 \mathrm{mM} \mathrm{KCl}$, $20 \mathrm{mM} \mathrm{MgSO}_{4}$ ) was used. All bacteria were grown at $37{ }^{\circ} \mathrm{C}$, except the temperature-sensitive strain $98 \mathrm{NK} 2(\mathrm{pkD} 46)$. Antibiotics were used at $50 \mu \mathrm{g} \mathrm{ml}^{-1}$ for kanamycin and $100 \mu \mathrm{g} \mathrm{ml}^{-1}$ for ampicillin.

Incubation with SCFAs. To simulate gastrointestinal levels of SCFAs, overnight cultures of respective strains were diluted $1: 120$ in LB buffered with $100 \mathrm{mM}$ MOPS (pH 6.7) and supplemented with either $95 \mathrm{mM}$ acetate, $60 \mathrm{mM}$ propionate and $17 \mathrm{mM}$ butyrate (colonic SCFA medium) or with $25 \mathrm{mM}$ acetate, $2.5 \mathrm{mM}$ propionate and $2.5 \mathrm{mM}$ butyrate (ileal SCFA medium). The $\mathrm{NaCl}$ concentration of the control medium (MOPS-buffered LB, pH 6.7) was adjusted to ensure equivalent osmolarity to the respective (ileal or colonic) SCFA medium. Cells were grown at $37{ }^{\circ} \mathrm{C}$ with agitation for 3 and/or $4 \mathrm{~h}$. All experiments were performed at least twice on different cultures, except when otherwise indicated. To examine the growth of $98 \mathrm{NK} 2$ following treatment with SCFAs, $100 \mu \mathrm{l}$ aliquots of cell culture, and serial dilutions thereof, were plated in duplicate on LB agar to determine c.f.u. $\mathrm{ml}^{-1}$ hourly for $5 \mathrm{~h}$.

Growth in iron-rich and iron-limited media. E. coli strains were grown at $37{ }^{\circ} \mathrm{C}$ with agitation in LB medium supplemented with $100 \mathrm{mM}$ MOPS (pH 6.7) and SCFAs, in standard LB medium ( $\mathrm{pH}$ 7.5) or in DMEM (Gibco) (without agitation), supplemented

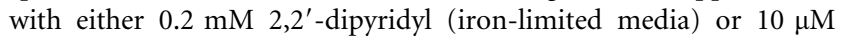
$\mathrm{FeSO}_{4}$ (iron-rich media).

Mutagenesis of 98NK2. Deletion of the fur and tonB genes and insertion of a kanamycin-resistance cassette were performed using the lambda Red recombinase system as described by Datsenko \& Wanner (2000). In order to do this, a kanamycin-resistance gene was amplified from plasmid pKD4 using high-fidelity PCR and the primer pairs d-tonB-f/d-tonB-r and d-fur-f/d-fur-r, for tonB and fur, respectively (Table 2). The resultant PCR products were purified and electroporated into E. coli strain $98 \mathrm{NK} 2$ harbouring the temperaturesensitive plasmid pkD46. Kanamycin-resistant, ampicillin-sensitive recombinants were checked by PCR using respective flanking region primers and the kanamycin-specific primers K1, K2 and Kt described by Datsenko \& Wanner (2000). Sequencing reactions were performed in order to confirm the deletion of the major portion of the respective gene, and confirmed mutants were designated $98 \mathrm{NK} 2 \Delta$ fur:: kan and 98NK2 2 tonB : : kan.

Isolation of total RNA. RNA was isolated from bacterial pellets using the RNeasy Mini kit (Qiagen) according to the manufacturer's instructions, and treated with RNase-free DNase (Roche) following the recommendations of the manufacturer. The purity of each RNA preparation was confirmed by one-step reverse transcription (RT)PCR (Access RT-PCR Core Reagents, Promega), with or without reverse transcriptase, using the $16 \mathrm{~S}$ rRNA-specific primers rrsH-f and rrsH-r (Table 2). The products were visualized after electrophoresis on a $2 \%$ TAE-agarose gel. In DNA-free RNA samples, PCR products were only seen in the presence of reverse transcriptase. RNA was further purified using an RNeasy Mini kit and the concentration and quality of RNA was determined by $A_{260 / 280}$ measurement. First-strand cDNA synthesis from equal amounts of total RNA was performed 
Table 1. Bacteria and plasmids used in this study

\begin{tabular}{|c|c|c|}
\hline Strain or plasmid & Description ${ }^{\star}$ & Reference/source \\
\hline \multicolumn{3}{|l|}{ E. coli strains } \\
\hline $98 \mathrm{NK} 2$ & STEC O113:H21 & Paton et al. (1999) \\
\hline $98 \mathrm{NK} 2-\mathrm{Cu}$ & STEC O113:H21, cured of megaplasmid & Paton et al. (2001) \\
\hline EDL933 & STEC O157:H7 & Riley et al. (1983) \\
\hline $86-24$ & STEC O157:H7 & Tarr et al. (1989) \\
\hline JM109 & E. coli $\mathrm{K}-12$ derivative & Yanisch-Perron et al. (1985) \\
\hline $98 \mathrm{NK} 2 \Delta i h a_{\mathrm{pO} 113}:: k a n$ & STEC O113:H21 $\Delta i h a_{\mathrm{pO} 113}:: k a n, \mathrm{Kn}^{\mathrm{R}}$ & Srimanote $(2003)$ \\
\hline $98 \mathrm{NK} 2 \Delta$ fur: : kan & STEC O113:H21 fur: : kan, $\mathrm{Kn}^{\mathrm{R}}$ & This study \\
\hline 98NK2 2 tonB: : kan & STEC O113:H21 tonB : : kan, $\mathrm{Kn}^{\mathrm{R}}$ & This study \\
\hline M15(pREP4) & E. coli $\mathrm{K}-12$ derivative, $\mathrm{Kn}^{\mathrm{R}}$ & Qiagen \\
\hline M15(pREP4)(pQiha) & Produces $\mathrm{His}_{6}-\mathrm{Iha}_{\mathrm{pO} 113}$ fusion protein, $\mathrm{Ap}^{\mathrm{R}} \mathrm{Kn}^{\mathrm{R}}$ & This study \\
\hline \multicolumn{3}{|l|}{ Plasmids } \\
\hline pQE-31 & Expression vector, $\mathrm{Ap}^{\mathrm{R}}$ & Qiagen \\
\hline pQiha & Expression vector, contains $i h a_{\mathrm{pO} 113}, \mathrm{Ap}^{\mathrm{R}}$ & This study \\
\hline pkD4 & Vector template for mutagenesis, $\mathrm{Ap}^{\mathrm{R}} \mathrm{Kn}^{\mathrm{R}}$ & Datsenko \& Wanner (2000) \\
\hline pkD46 & Red recombinase expression vector, $\mathrm{Ap}^{\mathrm{R}}$ & Datsenko \& Wanner (2000) \\
\hline
\end{tabular}

${ }^{\star} \mathrm{Kn}^{\mathrm{R}}$, kanamycin resistance; $\mathrm{Ap}^{\mathrm{R}}$, ampicillin resistance.

using random primers (Invitrogen) and SuperScript III Reverse Trancriptase (Invitrogen), as described by the manufacturer. cDNA was purified using a MiniElute PCR Purification kit (Qiagen) according to the recommendations of the Genisphere RNA amplification kit (http://www.genisphere.com/pdf/SenseAMP_Plus_ 12-15-06.pdf) and eluted with $10 \mu$ l elution buffer.

Two-step real-time PCR. The amount of mRNA extracted from bacteria and reverse transcribed into cDNA was measured by relative real-time PCR. Real-time PCR was performed in triplicate on a Rotorgene RG-2000 (Corbett Research) according to the manufacturer's instructions. Primers for iha, tonB and fur (Table 2) were designed using Oligo Explorer 1.2 (http://www.genelink.com/tools/gloe.asp). PCR amplifications were performed with $1 \mu 11: 60$-diluted
cDNA in a $25 \mu \mathrm{l}$ reaction mix containing $200 \mathrm{nM}$ each primer and $12.5 \mu$ Platinum SYBR Green qPCR Super Mix-UDG (Invitrogen). The amplification conditions were as follows: $50{ }^{\circ} \mathrm{C}$ for $2 \mathrm{~min}, 95{ }^{\circ} \mathrm{C}$ for $2 \mathrm{~min}$, and then 40 cycles of $95{ }^{\circ} \mathrm{C}$ for $30 \mathrm{~s}$ and $60{ }^{\circ} \mathrm{C}$ for $30 \mathrm{~s}$. The specificity of each PCR product was confirmed by melting curve analysis according to the manufacturer's instructions. For each gene the fold-differences were determined using the $2^{-\Delta \Delta C_{t}}$ method (Livak \& Schmittgen, 2001). Levels of expression of iha, tonB and fur were related to the constitutively expressed housekeeping gene $r r s H$ (16S rRNA). Expression data for iha, fur and tonB were analysed relative to the level of the respective gene in the untreated sample (control), and presented as a relative fold increase or decrease between treated and untreated samples, normalized to the level of $r r s H$ RNA. Statistical significance of differences between normalized $C_{\mathrm{t}}$ values were

Table 2. Oligonucleotide primers used in this study

Primer sequences derived from E. coli K-12, E. coli O157:H7 strain EDL933 and strain 86-24 or E. coli O113:H21 strain $98 \mathrm{NK} 2$ and strain E41 sequences, as deposited in the NCBI database.

\begin{tabular}{|ll|}
\hline Primer & \multicolumn{1}{c|}{ Sequence $\mathbf{5}^{\prime} \mathbf{z}^{\prime}{ }^{\prime}$} \\
\hline d-tonB-f & CGTTACTTTCGGTCTGCATTCATGGTGCTGTTGTGGCGGGTCTGTGTAGGCTGGAGCTGCT \\
d-tonB-r & ATTCACCACAATCCCACTGCCTGGCTTACCCGGCTCATAACGCCATATGAATATCCTCCTTAG \\
d-fur-f & ACCGCCCTAAAGAAAGCTGGCCTGAAAGTAACGCTTCCTCGTTGTGTAGGCTGGAGCTGCTTC \\
d-fur-r & AATCGCCTTCGGCACAGTGACCGTAAAGATAGAGACTGTGGTTCATATGAATATCCTCCTTAG \\
fur-f & TGGTTAGTCAGGCGAATGCC \\
fur-r & GACACAGCAACATCACCACG \\
iha-f & CTGACTAATGCAGCCGCCAG \\
iha-r & CCTCCGGTTTTACCCGTACC \\
iha ${ }_{\text {pO } 113} \mathrm{~F}$ & TGAGAAGGATCCGACTAATGCAGCCGCC \\
iha ${ }_{\mathrm{pO} 113} \mathrm{R}$ & TTTTGCAAGCTTCATGCCTGCTAACGGATA \\
rrsH-f & GAACGGTAACAGGAAGAAGC \\
rrsH-r & CGACGTTATGCGGTATTAGC \\
tonB-f & TTCATGGTGCTGTTGTGGCG \\
tonB-r & TTGTGGCGGTTCGAGATCAG \\
\hline
\end{tabular}


analysed by Student's unpaired $t$-test (two-tailed) using Graphpad Prism version 5.0.

Southern hybridization. DIG-labelled iha probe was generated by PCR using the PCR DIG Labelling Mix (Roche) with primers iha-f and iha-r and 98NK2 DNA as template. Three micrograms of EcoRIand BstXI-digested DNA was separated by electrophoresis on a $0.8 \%$ agarose gel. Southern transfer of separated DNA onto positively charged nylon membrane (Biodyne, Pall Corporation) was carried out as described by Maniatis et al. (1982). After transfer, DNA was fixed to the membrane by UV cross-linking. Membranes were prehybridized at $42{ }^{\circ} \mathrm{C}$ for $30 \mathrm{~min}$ in prehybridization buffer $[5 \times$ SSC, $0.1 \%(\mathrm{w} / \mathrm{v}) \quad N$-lauroylsarcosine, $0.2 \%(\mathrm{w} / \mathrm{v})$ SDS, $1 \%(\mathrm{w} / \mathrm{v})$ Blocking reagent; Roche] and incubated overnight with hybridization solution [ $5 \times$ SSC, $0.1 \%(\mathrm{w} / \mathrm{v}) \mathrm{N}$-lauroylsarcosine, $0.2 \%(\mathrm{w} / \mathrm{v})$ SDS, $1 \%(\mathrm{w} / \mathrm{v})$ Blocking reagent] containing the appropriate DIG-labelled iha-probe. Membranes were washed twice with $2 \times$ SSC/0.1\% SDS followed by two wash steps for 15 min with $0.5 \times$ SSC/0.1\% SDS at $65{ }^{\circ} \mathrm{C}$ under constant agitation. After blocking with $1 \%(\mathrm{w} / \mathrm{v})$ Blocking reagent in $0.1 \mathrm{M}$ maleic acid/0.15 M NaCl, pH 7.5, the membrane was probed with anti-DIG-AP Fab fragment (Roche) and bands were detected using chemiluminescent substrate CDP Star (Invitrogen).

Preparation of anti-Iha $\mathbf{p}_{\mathbf{p} 113}$ serum. In order to generate an Iha $_{\mathrm{pO} 113}$-specific serum, $i h a_{\mathrm{pO} 113}$ was expressed using Qiaexpressionist (Qiagen), resulting in production of a $\mathrm{His}_{6}$-Iha $\mathrm{IhO}_{\mathrm{pO} 13}$ fusion protein, whereby the $\mathrm{His}_{6}$-tag was fused to the $\mathrm{N}$ terminus of mature $\mathrm{Iha}_{\mathrm{pO} 113}$, removing the 38 aa signal sequence. In order to do this, $i h a_{\mathrm{pO} 113}$ was PCR-amplified using primers $i \mathrm{iha}_{\mathrm{pO} 113} \mathrm{~F}$ and iha $_{\mathrm{pO} 113} \mathrm{R}$, which incorporated BamHI and HindIII restriction sites, respectively (Table 2). The resultant PCR product was digested and ligated into pQE31 (Qiagen). Correct in-frame insertion of the $i h a_{\mathrm{pO} 113}$ fragment was confirmed by sequence analysis and the construct (pQiha) was transformed into the expression host E. coli M15(pREP4). For large-scale purification, an exponential-phase broth culture of E. coli M15(pREP4)(pQiha) containing $100 \mu \mathrm{g}$ ampicillin $\mathrm{ml}^{-1}$ and $25 \mu \mathrm{g}$ kanamycin $\mathrm{ml}^{-1}$ was induced by the addition of $2 \mathrm{mM}$ IPTG (Inalco Pharmaceutical) and incubated for $3 \mathrm{~h}$ with shaking at $37^{\circ} \mathrm{C}$. The cells were harvested by centrifugation and resuspended in $12 \mathrm{ml} 6 \mathrm{M}$ guanidine. $\mathrm{HCl}, 0.1 \mathrm{M}$ disodium hydrogen orthophosphate, $0.01 \mathrm{M}$ Tris/ $\mathrm{HCl}, \mathrm{pH} 8.0$, and stirred for $1 \mathrm{~h}$ at room temperature. The cell lysate was centrifuged $(10000 \mathrm{~g}$, $25 \mathrm{~min}, 4{ }^{\circ} \mathrm{C}$ ) and the supernatant was loaded onto a Ni-NTA (Probond, Invitrogen) column, pre-equilibrated with 10 column volumes of buffer A ( $0.5 \mathrm{M} \mathrm{NaCl}, 15 \mathrm{mM}$ imidazole), at a rate of $15 \mathrm{ml}$ per hour. After washing the column with 10 column volumes of buffer A, 20 column volumes of buffer B (8 M urea, $0.1 \mathrm{M}$ disodium hydrogen orthophosphate, $0.01 \mathrm{M}$ Tris/ $\mathrm{HCl}, \mathrm{pH} 8.0)$ and 20 column volumes of buffer $\mathrm{C}$ ( $8 \mathrm{M}$ urea, $0.1 \mathrm{M}$ disodium hydrogen orthophosphate, $0.01 \mathrm{M}$ Tris/ $\mathrm{HCl}, \mathrm{pH} 6.3,0.25 \mathrm{M} \mathrm{NaCl}, 5 \mathrm{mM}$ imidazole), the protein was eluted using $30 \mathrm{ml}$ of a $0-500 \mathrm{mM}$ imidazole gradient. Fractions $(3 \mathrm{ml})$ were collected and analysed by SDS-PAGE. Peak fractions were pooled and dialysed overnight at $4{ }^{\circ} \mathrm{C}$ against a decreasing concentration of urea $(8 \mathrm{M}-2 \mathrm{M})$, with dialysis continuing for a further $4 \mathrm{~h}$ in PBS pH 7.5 containing $2 \mathrm{M}$ urea in order to refold the protein. Six BALB/c mice were immunized by intraperitoneal injection of $10 \mu \mathrm{g}$ purified $\mathrm{Iha}_{\mathrm{pO} 113}$ in complete Freund's adjuvant, followed by two doses of $10 \mu \mathrm{g}$ purified $\mathrm{Iha}_{\mathrm{pO} 113}$ in incomplete Freund's adjuvant at 10 day intervals. Blood was collected by cardiac puncture 2 weeks after the third immunization, and serum was stored at $4{ }^{\circ} \mathrm{C}$.

Western blot analysis. After incubation under various conditions, the equivalent of $1 \times 10^{8}$ bacteria were pelleted by centrifugation $\left(4000 \mathrm{~g}, 5 \mathrm{~min}, 4{ }^{\circ} \mathrm{C}\right)$ and resuspended in $100 \mu \mathrm{l}$ SDS sample buffer [62.5 mM Tris pH 6.8, 2\%(w/v) SDS, $10 \%(\mathrm{v} / \mathrm{v})$ glycerol, $5 \%$ mercaptoethanol, $0.05 \%$ (w/v) bromophenol blue]. Proteins were separated by SDS-PAGE using a 4-20\% Bistris gradient gel (Invitrogen) according to the manufacturer's instructions and electrophoretically transferred onto PVDF membranes (Hybond, Amersham). Membranes were blocked for $1 \mathrm{~h}$ with $1 \times$ TTBS (Tris-buffered saline, $0.05 \%$ Tween 20 ) containing $5 \%$ skim milk and probed with mouse anti-His 6 -Iha $\mathrm{pO}_{\mathrm{pO} 13}$ serum, followed by incubation with goat anti-mouse immunoglobulin $\mathrm{G}$ conjugated to alkaline phosphatase (Bio-Rad). Bands were detected using a chromogenic nitro blue tetrazolium/5bromo-4-chloro-3-indolyl phosphate substrate.

\section{RESULTS}

\section{Homologues of iha in 98NK2}

iha homologues are found in several STEC and UPEC strains as single or multiple copies (Tarr et al., 2000). Therefore, we initially investigated the number of iha homologues in the hyper-virulent LEE-negative O113:H21 STEC 98NK2. Southern blot analysis of EcoRI- and BstXIdigested DNA of $98 \mathrm{NK} 2$ and its megaplasmid-cured derivative $(98 \mathrm{NK} 2-\mathrm{Cu})$ revealed two iha probe-reactive bands in each of the $98 \mathrm{NK} 2$ digests, but only one in either of the $98 \mathrm{NK} 2-\mathrm{Cu}$ digests (result not presented). Thus, $98 \mathrm{NK} 2$ contains two copies of iha, one located on megaplasmid pO113 (as already deposited in GenBank; accession nos NC_007365 and AF399919) and one residing on the chromosome.

\section{Regulation of iha expression in 98NK2 by iron}

As a further preliminary experiment, we examined whether iha expression in the LEE-negative STEC O113:H21 strain $98 \mathrm{NK} 2$ is regulated by iron and the Fur protein, as previously reported for UPEC and the LEE-positive STEC O157:H7 strain 86-24 (Leveille et al., 2006; Rashid et al., 2006b). Since Iha functions as a siderophore receptor and the capacity of Iha to transport siderophores is TonBdependent, we also investigated ton $B$ expression under the same conditions. Given the fact that Fur functions as a repressor of a broad range of genes, including iha, we also examined fur gene expression. In order to do this, 98NK2 was grown in LB and DMEM media with or without $0.2 \mathrm{mM} 2,2^{\prime}$-dipyridyl to simulate iron-limiting conditions. RNA was isolated from exponentially growing cultures after $3 \mathrm{~h}$ incubation in the case of LB and after $6 \mathrm{~h}$ in the case of DMEM, since the growth rate of E. coli in tissue culture media is retarded. Two-step real-time RTPCR was then used to measure levels of iha, tonB and fur mRNA, normalized against 16S rRNA $(r r s H)$, in treated versus untreated cultures and results are presented as a relative fold increase/decrease (Fig. 1a). After growth in LB supplemented with $2,2^{\prime}$-dipyridyl we observed a 20.3 -fold increase in iha expression. Coincidentally, a 42.4-fold increase in ton $B$ expression was detected, whereas fur expression in $98 \mathrm{NK} 2$ was relatively unaffected (1.8-fold increase). In DMEM, an enhancement in expression of iha (9.3-fold) and tonB (3.1-fold) was detectable following growth in DMEM supplemented with 2,2'-dipyridyl 
(a)

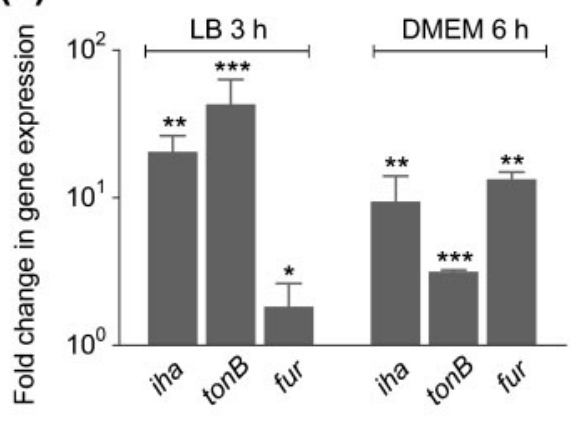

(b)

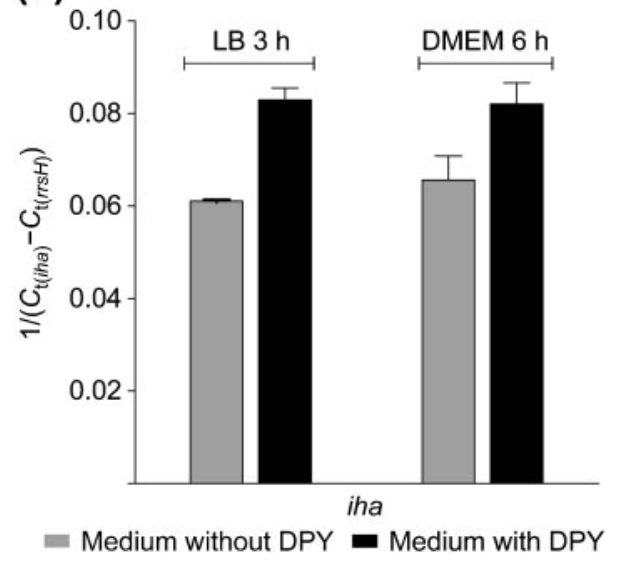

Fig. 1. Effect of 2,2'-dipyridyl (DPY) on expression of iha, tonB and fur in E. coli O113:H21 strain 98NK2, determined by real-time RT-PCR. Cells were grown for $3 \mathrm{~h}$ in LB and for $6 \mathrm{~h}$ in DMEM, supplemented with $0.2 \mathrm{mM}$ 2,2'-dipyridyl. (a) Data are presented as the increase ( $n$-fold) in mRNA expression compared to the control grown in LB or DMEM without 2,2' -dipyridyl, normalized to rrs $\mathrm{H}$ expression. Data are the mean \pm SD of two independent experiments, each assayed in triplicate. ${ }^{*}, P<0.05 ;{ }^{* *}, P<0.01 ;{ }^{* \star *}$, $P<0.005$; Student's unpaired two-tailed $t$-test. (b) Relative iha mRNA levels in 98NK2 determined by real-time RT-PCR as described above. Real-time RT-PCR data for each gene were normalized against those obtained for the 16S rRNA ( $r r s H)$ mRNA control using the formula $1 /\left(\mathrm{C}_{\mathrm{t}(\text { iha })}-\mathrm{C}_{\mathrm{t}(\text { rrsH })}\right)$. Data are the mean \pm SD of two independent experiments, each assayed in triplicate.

relative to DMEM alone. Furthermore, a 13.2-fold increase in expression of fur was observed.

We also investigated effects on Iha production by SDSPAGE and Western immunoblotting using anti-Iha $\mathrm{pO}_{\mathrm{pO} 13}$. Whole-cell lysates were analysed after $4 \mathrm{~h}$ incubation in LB supplemented with $2,2^{\prime}$-dipyridyl or $\mathrm{FeSO}_{4}$, or after $7 \mathrm{~h}$ in the case of DMEM (Fig. 2). Immunoreactive bands of approximately $70 \mathrm{kDa}$, corresponding in size to the deduced molecular mass of mature $\mathrm{Iha}_{\mathrm{pO} 113}$, were evident in all samples. In cells grown in LB, basal production of Iha was low, presumably due to the presence of sufficient amounts of iron in the medium to repress iha (Fig. 2). In



Fig. 2. Immunoblot analysis of whole-cell lysates of $98 \mathrm{NK} 2$ using anti-lha $\mathrm{pO113}_{\text {. }}$ Cells were grown in LB for $4 \mathrm{~h}$ or in DMEM for $7 \mathrm{~h}$

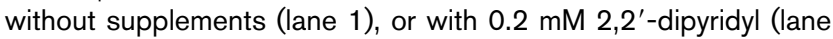
2) or $10 \mu \mathrm{M} \mathrm{FeSO}_{4}$ (lane 3). Lysates were separated by SDSPAGE, blotted and probed with anti-lha. The bands represent the $70 \mathrm{kDa}$ lha antigen. The blot shown is representative of three independent experiments.

DMEM, basal Iha production was higher than in LB, because the level of iron is sufficiently low to partially derepress iha. Increased iha expression in DMEM is also apparent when the absolute level of iha mRNA relative to the internal standard $r r s H\left(C_{\mathrm{t}(i h a)}-C_{\mathrm{t}(r r s H)}\right.$; see Methods) is compared for DMEM- and LB-grown cells (Fig. 1b). The observation that Iha is better expressed in DMEM than LB medium has been reported previously for O157:H7 STEC, non-O157:H7 STEC and UPEC strains (Johnson et al., 2005; Rashid et al., 2006b; Schmidt et al., 2001).

In LB supplemented with 2,2'-dipyridyl, Iha production was strongly induced (Fig. 2). In spite of the higher baseline expression of tha in DMEM, addition of 2,2'-dipyridyl resulted in a further increase in Iha expression, presumably due to full de-repression (Fig. 2). Under de-repressed conditions, overall Iha expression was similar in both media, at both the protein (Fig. 2) and mRNA level (Fig. 1b). As expected, addition of $\mathrm{FeSO}_{4}$ to either DMEM or LB fully repressed Iha production, with levels similarly low in both media (Fig. 2). Collectively, the above RT-PCR and immunoblot findings are consistent with Fur-mediated repression of iha in $98 \mathrm{NK} 2$ by iron in both media.

\section{Effect of SCFAs on iha expression}

SCFAs are the dominant anions in the mammalian intestinal tract, with acetate, propionate and butyrate accounting for $85-95 \%$ of total SCFAs in all regions of the colon (Cummings \& Macfarlane, 1991). To simulate colonic SCFA concentrations we used a mixture of $95 \mathrm{mM}$ acetate, $60 \mathrm{mM}$ propionate and $17 \mathrm{mM}$ butyrate (55\% acetate, $35 \%$ propionate and $10 \%$ butyrate) in MOPS-buffered LB (see Methods); for ileal SCFA concentrations, we used a mixture of $25 \mathrm{mM}$ acetate, $2.5 \mathrm{mM}$ propionate and $2.5 \mathrm{mM}$ butyrate $(85 \%$ acetate, $7.5 \%$ propionate and $7.5 \%$ butyrate) (Cummings et al., 1987; Cummings \& Macfarlane, 1991; Lawhon et al., 2002; Macfarlane et al., 2006). We then examined iha gene expression in response to exposure to SCFAs. 
Initially, effects of SCFAs on growth of $98 \mathrm{NK} 2$ were investigated. Growth in ileal SCFA medium had no effect on growth rate (Fig. 3a). However, colonic SCFA medium retarded growth, increasing generation time to about $60 \mathrm{~min}$, compared with $30 \mathrm{~min}$ for control medium (MOPS-buffered LB of equivalent osmolarity) (Fig. 3b).

To examine the expression profile of iha and other relevant STEC genes, real-time RT-PCR analysis was carried out on RNA isolated from $98 \mathrm{NK} 2$ after 3 and/or $4 \mathrm{~h}$ incubation in ileal or colonic SCFA media, or control medium (see Methods). Time points were chosen on the basis of the growth curves in Fig. 3. No significant increase in expression of either iha, fur or tonB was observed after $3 \mathrm{~h}$ growth in ileal SCFA medium (result not shown). Western blot analysis confirmed these results at the protein level for Iha (data not shown). However, 98NK2 exhibited marked iha upregulation following growth in colonic SCFA medium (20.1- and 11.9-fold after 3 and $4 \mathrm{~h}$, respectively) (Fig. 4). A similarly marked increase in ton $B$ expression was also observed (60.9- and 43.2-fold after 3 and $4 \mathrm{~h}$, respectively). Upregulation of fur was less dramatic, but nevertheless significant (4.2-fold at both time points).

\section{(a)}

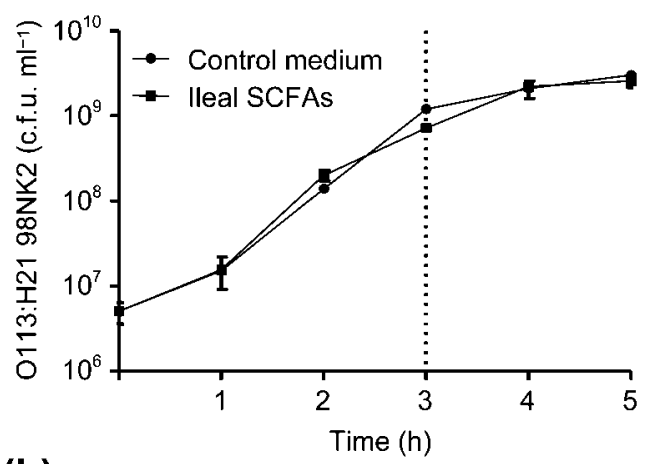

(b)

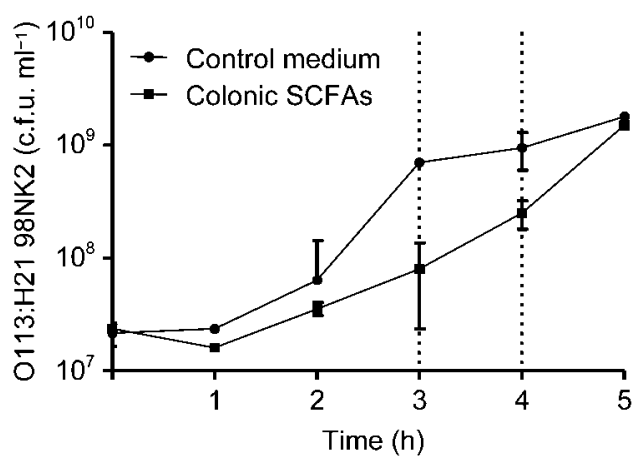

Fig. 3. Effect of ileal (a) and colonic (b) concentrations of SCFAs on growth of $E$. coli $98 \mathrm{NK} 2$. Growth was measured by viable count (c.f.u. $\mathrm{ml}^{-1}$; data are the mean $\pm \mathrm{SD}, n=2$ ), as described in Methods. The dotted lines indicate time points selected for RNA isolation.

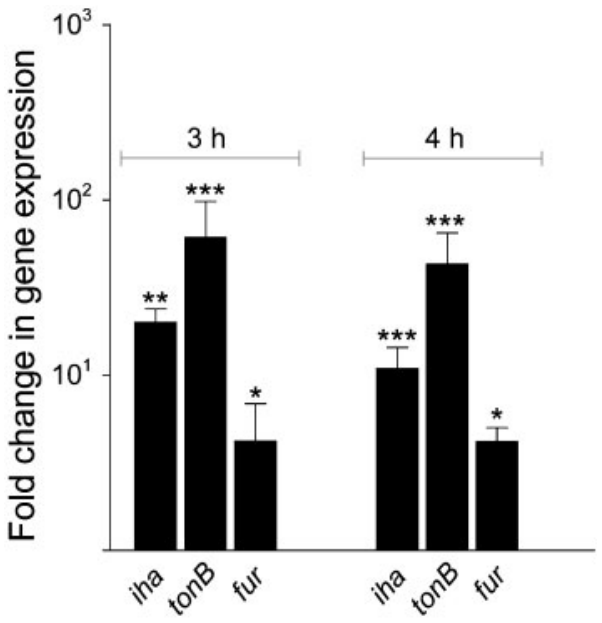

Fig. 4. Gene expression levels of $i h A$, ton $B$ and fur as determined by real-time RT-PCR after growth of $98 \mathrm{NK} 2$ for $3 \mathrm{~h}$ or $4 \mathrm{~h}$ in colonic SCFA medium. Data are presented as the increase ( $n$-fold) in gene expression levels compared to $98 \mathrm{NK} 2$ grown in control medium, normalized to $\mathrm{rrs} H$ expression. Data are the mean $\pm \mathrm{SD}$ of three independent experiments, each assayed in triplicate. *, $P<0.05 ;{ }^{* *}, P<0.01 ;{ }^{* \star *}, P<0.005$; Student's unpaired two-tailed $t$-test.

Next, we investigated whether growth in colonic SCFA medium had the same effect on iha expression in the LEEpositive STEC strains EDL933 and 86-24. As indicated in Fig. 5, both strains exhibited statistically significant upregulation of iha expression, albeit to a lesser extent

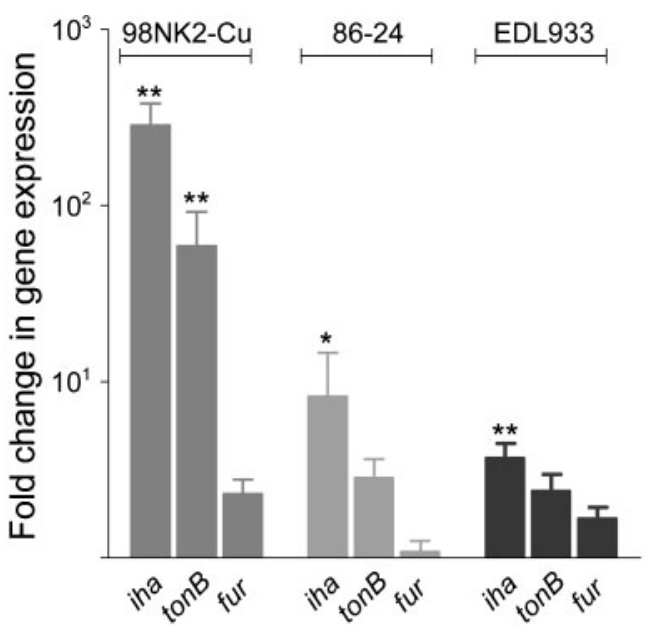

Fig. 5. Gene expression levels of iha, tonB and fur in $98 \mathrm{NK} 2-\mathrm{Cu}$, 86-24 and EDL933 after growth in colonic SCFA medium for $3 \mathrm{~h}$. Data are presented as the increase/decrease ( $n$-fold) in expression levels compared to cells grown in control medium, normalized to $r r s$ expression. Data are the mean $\pm S D$ of two independent experiments, each assayed in triplicate. ${ }^{*}, P<0.05$; ${ }^{*}, P<0.01$; Student's unpaired two-tailed $t$-test. 
than in 98NK2. EDL933 contains two identical copies of iha (located on O islands OI-41 and OI-48) (Taylor et al., 2002) and exhibited a 3.7-fold increase after $3 \mathrm{~h}$, whereas 86-24, with only one iha copy (Tarr et al., 2000), showed a stronger induction (8.2-fold after $3 \mathrm{~h}$ ). Induction of tonB was only modest compared to that seen in 98NK2 (2.8-fold for 86-24 and 2.4-fold for EDL933). Colonic SCFA medium had no significant effect on fur expression in either strain (Fig. 5).

Production of Iha was also investigated by Western immunoblotting with $\mathrm{Iha}_{\mathrm{pO} 113}$ antibody (Fig. 6). All STEC strains exhibited marked upregulation of Iha production when grown in colonic SCFA medium relative to the control medium. However, total Iha production in colonic SCFA medium was greater for 98NK2 than for 8624, which in turn was greater than for EDL933.

To investigate whether regulatory elements present on the megaplasmid pO113 affect iha expression, we also investigated the response of the megaplasmid-cured derivative of 98NK2 (98NK2-Cu) to growth in colonic SCFA medium for $3 \mathrm{~h}$. As previously shown for the wild-type, $98 \mathrm{NK} 2-\mathrm{Cu}$ exhibited a marked upregulation of iha expression at the mRNA level (285.6-fold) (Fig. 5) and protein level (Fig. 6). Also, tonB and fur showed similar induction to that observed in 98NK2 (58.7- and 2.3-fold, respectively) (Fig. 5). We also examined the degree of colonic SCFA-induced iha upregulation in $98 \mathrm{NK} 2 \Delta i h a_{\mathrm{pO} 113}:: k a n$, in which the megaplasmidencoded copy of iha has been inactivated by insertion of a non-polar kanamycin resistance cassette. We observed a 17.2-fold increase in expression of the remaining chromosomal copy of iha in this mutant (data not presented), which is similar to the observed iha expression in 98NK2 after the same period of induction. Likewise, colonic SCFAinduced increases in expression of tonB and fur were similar to those for 98NK2 (24.6-fold and 2.6-fold, respectively) (data not presented).

Examination of the absolute iha mRNA levels for the strains 98NK2, 98NK2-Cu, 98NK2 $\Delta i h a_{\mathrm{pO} 113}:$ : kan, EDL933 and 86-24 relative to the internal standard $r r s H$ $\left(C_{\mathrm{t}(i h a)}-C_{\mathrm{t}(r r s H)}\right)$ shows that the iha mRNA level under

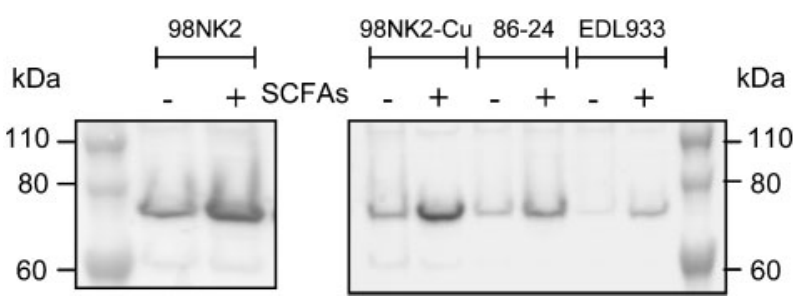

Fig. 6. Immunoblot analysis of whole-cell lysates of 98NK2, 98NK2-Cu, 86-24 and EDL933 with anti-lhapO113. Cells were grown in colonic SCFA medium (+) or control medium (-) for $4 \mathrm{~h}$. Lysates were then separated by SDS-PAGE, blotted and probed with anti-lha. The bands represent the $70 \mathrm{kDa}$ lha antigen. The blot shown is representative of two independent experiments. both basal and colonic SCFA conditions was greater for LEE-negative STEC 98NK2 than for either LEE-positive STEC EDL933 or 86-24 (Fig. 7). This is not simply a gene dosage effect; the iha mRNA concentration under both induced and non-induced conditions in 86-24 (which has a single chromosomal copy of $i h a$ ) is not dissimilar to that in EDL933 (which has two chromosomal iha copies) under the respective conditions. $98 \mathrm{NK} 2$ has a single chromosomal copy of iha, as well as one on the (low copy number) megaplasmid pO113. However, 98NK2 $\Delta i h a_{\mathrm{pO} 113}:: k a n$, which retains only the single chromosomal copy of iha, has a similar iha mRNA concentration to that observed in 98NK2, in either base or colonic SCFA medium (Fig. 7). On the other hand, the megaplasmid-cured derivate of 98NK2 exhibited a decreased iha mRNA level compared to 98NK2 under non-induced conditions, but the iha mRNA level under induced conditions was similar to 98NK2.

\section{Regulatory interactions between colonic SCFAs and iron}

We have shown above that supplementation of LB with either 2,2'-dipyridyl (Fig. 1) or colonic SCFAs (Fig. 4) causes an almost identical upregulation of iha, tonB and fur in 98NK2 (approx. 20-, 40- and 2-4-fold, respectively, in both conditions). To assess whether $\mathrm{Fe}$ availability and SCFA composition interact in terms of iha regulation, 98NK2 was grown in colonic SCFA medium supplemented with either $0.2 \mathrm{mM} 2,2^{\prime}$-dipyridyl or $10 \mu \mathrm{M} \mathrm{FeSO}_{4}$. Addition of 2,2'-dipyridyl to colonic SCFA medium caused no further increase in expression of any of the genes (iha, tonB and fur were upregulated 15.4-, 39.4- and 2.1-fold, respectively) (Fig. 8a). Addition of $\mathrm{FeSO}_{4}$ to colonic SCFA medium also resulted in a similar expression pattern to



Fig. 7. Relative iha mRNA levels in 98NK2, 98NK2-Cu, 98NK2 $\Delta$ iha $a_{\mathrm{pO} 113}:$ :kan, 86-24 and EDL933 after growth in colonic SCFA medium or control medium for $3 \mathrm{~h}$. Real-time RTPCR data for each gene were normalized against those obtained for the 16S rRNA (rrs $\mathrm{H})$ mRNA control using the formula $1 /\left(C_{\mathrm{t}(\text { iha })}-C_{\mathrm{t}(\text { rrs } H)}\right)$. Data are the mean $\pm \mathrm{SD}$ of two independent experiments, each assayed in triplicate. 

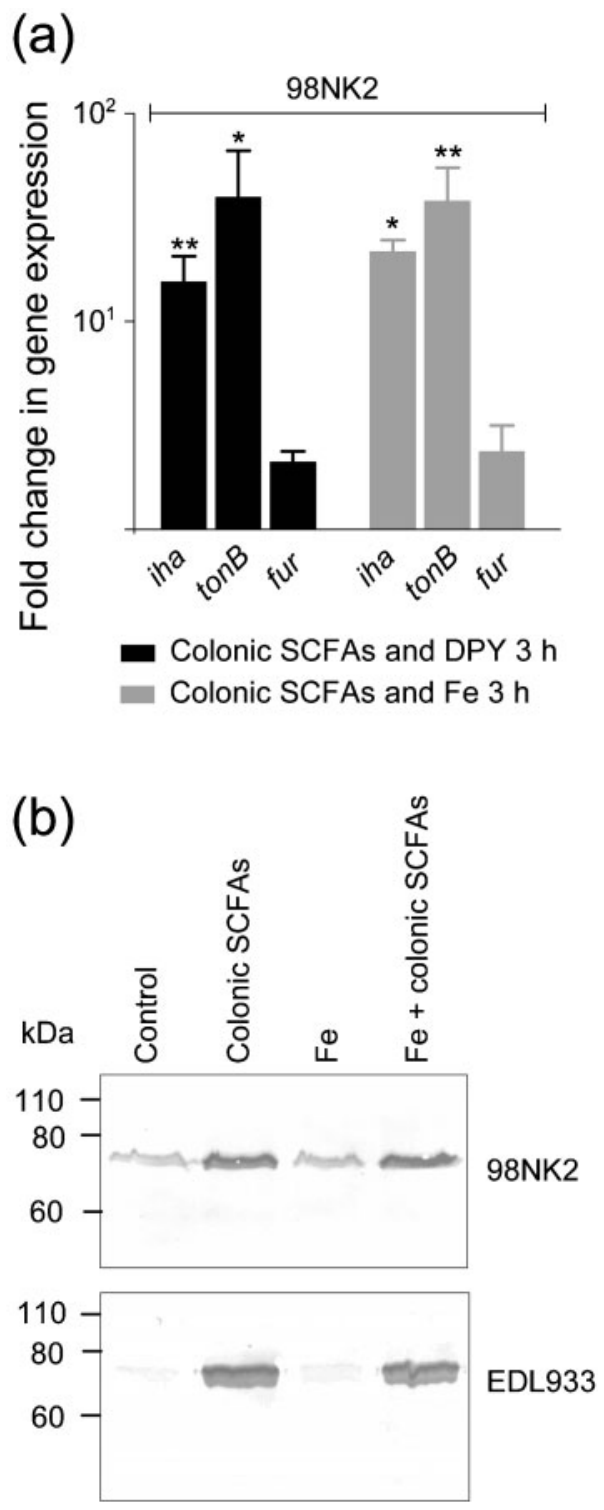

Fig. 8. Effect of iron and SCFAs on iha expression. (a) Expression levels of iha, tonB and fur in $98 \mathrm{NK} 2$ determined by real-time RT-PCR. Cells were grown for $3 \mathrm{~h}$ in colonic SCFA medium supplemented

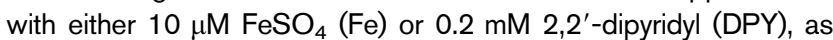
indicated. Data are presented as the increase/decrease ( $n$-fold) in expression levels compared to cells grown in control medium, normalized to $\mathrm{rrs} H$ expression. Data are the mean $\pm \mathrm{SD}$ of two independent experiments, each assayed in triplicate. ${ }^{*}, P<0.05$; **, $P<0.01$; Student's unpaired two-tailed $t$-test. (b) Western immunoblot. 98NK2 or EDL933 was grown in colonic SCFA medium or control medium, with or without $10 \mu \mathrm{M} \mathrm{FeSO}_{4}$, for $4 \mathrm{~h}$. Lysates were then separated by SDS-PAGE, blotted and probed with antiIha. The bands represent the $70 \mathrm{kDa}$ lha antigen. The blot shown is representative of two independent experiments.

that in colonic SCFA alone (21.5-, 37.8- and 2.4-fold upregulation for iha, tonB and fur, respectively) (Fig. 8a). The effect of $\mathrm{Fe}$ on Iha expression in the presence of colonic SCFAs was also examined by Western blotting in both $98 \mathrm{NK} 2$ and EDL933 (Fig. 8b). In both cases, addition of $10 \mu \mathrm{M} \mathrm{FeSO}_{4}$ had no effect on the strong induction of Iha by colonic SCFAs. Thus, colonic SCFAs are capable of overriding $\mathrm{Fe}$-mediated repression of tha expression in STEC.

\section{iha expression in 98NK2 $\Delta$ fur: : $k a n$ and 98NK2 $\Delta$ tonB : : kan}

To examine whether Fur has any role in the regulation of iha transcription in $98 \mathrm{NK} 2$ under colonic conditions, a fur deletion mutant was constructed as described in Methods. However, colonic SCFA conditions strongly inhibited growth of $98 \mathrm{NK} 2 \Delta f u r:$ kan, preventing transcriptional analysis. We also examined the effect of deletion of ton $B$, in view of the fact that its expression in response to ironchelation or colonic SCFA conditions paralleled that of iha in all STEC strains studied. After $3 \mathrm{~h}$ growth of 98NK2 2 tonB: : kan in colonic SCFA medium, iha expression was upregulated approximately 20-fold (data not shown). Thus, deletion of tonB has no effect on iha expression.

\section{DISCUSSION}

Iha is a potentially important accessory virulence factor for several pathotypes of E. coli, including STEC, UPEC and avian-pathogenic strains (Ewers et al., 2007; Johnson et al., 2000; Ons et al., 2007; Rodriguez-Siek et al., 2005; Tarr et al., 2000; Touati, 2000), functioning as an adhesin and, at least for UPEC, as a catecholate siderophore receptor (Leveille et al., 2006). This latter function is consistent with the fact that iha is induced under iron-limiting conditions and is subject to Fur-mediated repression in iron-replete environments in both UPEC and O157:H7 STEC strains (Leveille et al., 2006; Rashid et al., 2006b), as well as in the hyper-virulent LEE-negative STEC strain 98NK2, as shown in this study. However, the mammalian gut is a complex environment and many other compounds may impact on virulence gene expression. For example, the gut, particularly the colon, is rich in SCFAs such as acetate, propionate and butyrate, which are produced by commensal fermentative flora e.g. Lactobacillus sp. and Bifidobacteria sp. (Cummings et al., 1987, 2001; Cummings \& Macfarlane, 1991; Macfarlane et al., 1992, 2006; Salminen et al., 1998). In this study we have shown that growth in media supplemented with SCFAs simulating colonic conditions strongly induced iha transcription and expression of Iha protein in two well-characterized O157:H7 STEC strains (EDL933 and 86-24) and in the O113:H21 strain 98NK2. No such induction was observed under ileal SCFA conditions. These findings are consistent with the belief that the colon, rather than the ileum, is the preferred site of STEC colonization in humans (Paton \& Paton, 1998).

Whilst all three STEC strains exhibited iha induction in colonic SCFA medium, the strength of the induction (i.e. 
fold-increase) at the mRNA level (judged by real-time RTPCR), and the total amount of Iha produced (judged by Western blotting) appeared to be greater in $98 \mathrm{NK} 2$ than in either of the O157:H7 strains. This is also evident from comparison of the absolute iha mRNA levels for the various strains relative to the internal standard $r r s \mathrm{H}$. Under both basal and colonic SCFA conditions, iha mRNA concentration was greater for $98 \mathrm{NK} 2$ than for either EDL933 or 86-24 (Fig. 7). One possible explanation may be strain-specific DNA sequence polymorphisms upstream of the iha promoter. Comparison of GenBank entries indicates that there are 14 nucleotide differences in the $100 \mathrm{nt}$ region upstream of the iha transcription start site, including polymorphisms at positions $-85,-10$ and -1 , and within the putative Fur-binding site, between 98NK2 and both 86-24 and EDL933 (data not presented). Rashid et al. (2006b) have not only shown that a nucleotide exchange at position -85 caused higher iha expression in CFT073 than in 86-24, but also suggested that additional strain-specific factors, such as repressors, activators and additional nucleotide polymorphisms, may play a role in differential iha expression. These polymorphisms may well account for the observed differences in overall iha expression both under basal conditions, and in the presence of colonic SCFAs.

An important finding of the present study is that for both the LEE-negative O113:H21 STEC 98NK2 and the LEEpositive O157:H7 STEC EDL933, colonic SCFA-mediated induction of iha in $98 \mathrm{NK} 2$ could not be repressed by supplementation of the medium with $\mathrm{FeSO}_{4}$. The inability of exogenous iron to repress iha in colonic SCFA medium is not due to poor expression of fur in either strain. Indeed, the total fur mRNA concentration was greater after growth in colonic SCFAs than in control medium (result not shown). Although the precise mechanism whereby colonic SCFAs induce iha expression in STEC is not understood, one can imagine a model whereby a SCFA-induced transcriptional activator interacts with the iha promoter region, activating transcription by competitive displacement of Fur.

The findings of this study indicate the potential for SCFA composition to modulate expression of virulence-related STEC genes in different parts of the human gastrointestinal tract. Inter-species variations in gut microflora affecting intestinal SCFA composition may also explain the previously observed differences in expression of several STEC virulence genes (including iha) in extracts of bovine versus human faeces (Rashid et al., 2006a). At least for iha, upregulation in the human colon (but not in the ileum) may enhance colonization capacity in what is believed to be the preferred host niche. Moreover, given the fact that Iha may function as both an adhesin and a siderophore receptor (Leveille et al., 2006; Rashid et al., 2006b), upregulation of Iha by colonic SCFAs, along with TonB, which is also required for siderophore uptake, may increase the iron-scavenging capacity in the more anaerobic colonic environment. This may be important for E. coli energymetabolism, since deployment of anaerobic energy-gen- erating enzymes containing multiple $\mathrm{Fe}-\mathrm{S}$ clusters, rather than iron-free flavoproteins in the respiratory chain, would dramatically increase the demand for iron.

\section{ACKNOWLEDGEMENTS}

This work was supported by Program Grant 284214 and Project Grant 565359 from the National Health and Medical Research Council (NHMRC) (to J.C.P. and A. W.P.). S. H. is a recipient of a German Research Foundation (Deutsche Forschungsgemeinschaft, DFG) Research Fellowship; J. C. P. is a NHMRC Australia Fellow. We are also grateful to Alastair McEwan for helpful discussions.

\section{REFERENCES}

Arnold, C. N., McElhanon, J., Lee, A., Leonhart, R. \& Siegele, D. A. (2001). Global analysis of Escherichia coli gene expression during the acetate-induced acid tolerance response. J Bacteriol 183, 2178-2186.

Cummings, J. H. \& Macfarlane, G. T. (1991). The control and consequences of bacterial fermentation in the human colon. J Appl Bacteriol 70, 443-459.

Cummings, J. H., Pomare, E. W., Branch, W. J., Naylor, C. P. \& Macfarlane, G. T. (1987). Short chain fatty acids in human large intestine, portal, hepatic and venous blood. Gut 28, 1221-1227.

Cummings, J. H., Macfarlane, G. T. \& Englyst, H. N. (2001). Prebiotic digestion and fermentation. Am J Clin Nutr 73, 415S-420S.

Datsenko, K. A. \& Wanner, B. L. (2000). One-step inactivation of chromosomal genes in Escherichia coli K-12 using PCR products. Proc Natl Acad Sci U S A 97, 6640-6645.

Erickson, M. C. \& Doyle, M. P. (2007). Food as a vehicle for transmission of Shiga toxin-producing Escherichia coli. J Food Prot 70, 2426-2449.

Ewers, C., Li, G., Wilking, H., Kiessling, S., Alt, K., Antao, E. M., Laturnus, C., Diehl, I., Glodde, S. \& other authors (2007). Avian pathogenic, uropathogenic, and newborn meningitis-causing Escherichia coli: how closely related are they? Int J Med Microbiol 297, 163-176.

Frankel, G., Phillips, A. D., Rosenshine, I., Dougan, G., Kaper, J. B. \& Knutton, S. (1998). Enteropathogenic and enterohaemorrhagic Escherichia coli: more subversive elements. Mol Microbiol 30, 911-921.

Gantois, I., Ducatelle, R., Pasmans, F., Haesebrouck, F., Hautefort, I., Thompson, A., Hinton, J. C. \& Van Immerseel, F. (2006). Butyrate specifically down-regulates Salmonella pathogenicity island 1 gene expression. Appl Environ Microbiol 72, 946-949.

Gilbert, R. A., Tomkins, N., Padmanabha, J., Gough, J. M., Krause, D. O. \& McSweeney, C. S. (2005). Effect of finishing diets on populations and prevalence of enterohaemorrhagic E. coli virulence genes in cattle faeces. J Appl Microbiol 99, 885-894.

Johnson, J. R., Russo, T. A., Tarr, P. I., Carlino, U., Bilge, S. S., Vary, J. C., Jr \& Stell, A. L. (2000). Molecular epidemiological and phylogenetic associations of two novel putative virulence genes, iha and iroN(E. coli), among Escherichia coli isolates from patients with urosepsis. Infect Immun 68, 3040-3047.

Johnson, J. R., Jelacic, S., Schoening, L. M., Clabots, C., Shaikh, N., Mobley, H. L. \& Tarr, P. I. (2005). The IrgA homologue adhesin Iha is an Escherichia coli virulence factor in murine urinary tract infection. Infect Immun 73, 965-971.

Karmali, M. A. (1989). Infection by verocytotoxin-producing Escherichia coli. Clin Microbiol Rev 2, 15-38.

Karmali, M. A., Petric, M., Lim, C., Fleming, P. C., Arbus, G. S. \& Lior, H. (1985). The association between idiopathic hemolytic uremic 
syndrome and infection by verotoxin-producing Escherichia coli. J Infect Dis 151, 775-782.

Kwon, Y. M. \& Ricke, S. C. (1998). Induction of acid resistance of Salmonella typhimurium by exposure to short-chain fatty acids. Appl Environ Microbiol 64, 3458-3463.

Lawhon, S. D., Maurer, R., Suyemoto, M. \& Altier, C. (2002). Intestinal short-chain fatty acids alter Salmonella typhimurium invasion gene expression and virulence through BarA/SirA. Mol Microbiol 46, 1451-1464.

Leveille, S., Caza, M., Johnson, J. R., Clabots, C., Sabri, M. \& Dozois, C. M. (2006). Iha from an Escherichia coli urinary tract infection outbreak clonal group A strain is expressed in vivo in the mouse urinary tract and functions as a catecholate siderophore receptor. Infect Immun 74, 3427-3436.

Litwin, C. M. \& Calderwood, S. B. (1993). Role of iron in regulation of virulence genes. Clin Microbiol Rev 6, 137-149.

Livak, K. J. \& Schmittgen, T. D. (2001). Analysis of relative gene expression data using real-time quantitative PCR and the $2^{-\Delta \Delta C_{t}}$ method. Methods 25, 402-408.

Macfarlane, G. T., Gibson, G. R. \& Cummings, J. H. (1992). Comparison of fermentation reactions in different regions of the human colon. J Appl Bacteriol 72, 57-64.

Macfarlane, S., Macfarlane, G. T. \& Cummings, J. H. (2006). Review article: prebiotics in the gastrointestinal tract. Aliment Pharmacol Ther 24, 701-714.

Maniatis, T., Fritsch, E. F. \& Sambrook, J. (1982). Molecular Cloning: a Laboratory Manual. Cold Spring Harbor, NY: Cold Spring Harbor Laboratory.

Nataro, J. P. \& Kaper, J. B. (1998). Diarrheagenic Escherichia coli. Clin Microbiol Rev 11, 142-201.

Ons, E., Bleyen, N., Tuntufye, H. N., Vandemaele, F. \& Goddeeris, B. M. (2007). High prevalence iron receptor genes of avian pathogenic Escherichia coli. Avian Pathol 36, 411-414.

Paton, J. C. \& Paton, A. W. (1998). Pathogenesis and diagnosis of Shiga toxin-producing Escherichia coli infections. Clin Microbiol Rev 11, 450-479.

Paton, A. W., Woodrow, M. C., Doyle, R. M., Lanser, J. A. \& Paton, J. C. (1999). Molecular characterization of a Shiga toxigenic Escherichia coli O113:H21 strain lacking eae responsible for a cluster of cases of hemolytic-uremic syndrome. J Clin Microbiol 37, 3357-3361.

Paton, A. W., Srimanote, P., Woodrow, M. C. \& Paton, J. C. (2001). Characterization of Saa, a novel autoagglutinating adhesin produced by locus of enterocyte effacement-negative Shiga-toxigenic Escherichia coli strains that are virulent for humans. Infect Immun 69, 6999-7009.

Postle, K. \& Kadner, R. J. (2003). Touch and go: tying TonB to transport. Mol Microbiol 49, 869-882.

Rashid, R. A., Tabata, T. A., Oatley, M. J., Besser, T. E., Tarr, P. I. \& Moseley, S. L. (2006a). Expression of putative virulence factors of Escherichia coli O157:H7 differs in bovine and human infections. Infect Immun 74, 4142-4148.
Rashid, R. A., Tarr, P. I. \& Moseley, S. L. (2006b). Expression of the Escherichia coli IrgA homolog adhesin is regulated by the ferric uptake regulation protein. Microb Pathog 41, 207-217.

Riley, L. W., Remis, R. S., Helgerson, S. D., McGee, H. B., Wells, J. G., Davis, B. R., Hebert, R. J., Olcott, E. S., Johnson, L. M. \& other authors (1983). Hemorrhagic colitis associated with a rare Escherichia coli serotype. N Engl J Med 308, 681-685.

Rodriguez-Siek, K. E., Giddings, C. W., Doetkott, C., Johnson, T. J. \& Nolan, L. K. (2005). Characterizing the APEC pathotype. Vet Res 36, 241-256.

Salminen, S., Bouley, C., Boutron-Ruault, M. C., Cummings, J. H., Franck, A., Gibson, G. R., Isolauri, E., Moreau, M. C., Roberfroid, M. \& Rowland, I. (1998). Functional food science and gastrointestinal physiology and function. Br J Nutr 80 (Suppl 1), S147-S171.

Schmidt, H., Zhang, W. L., Hemmrich, U., Jelacic, S., Brunder, W., Tarr, P. I., Dobrindt, U., Hacker, J. \& Karch, H. (2001). Identification and characterization of a novel genomic island integrated at $s e l C$ in locus of enterocyte effacement-negative, Shiga toxin-producing Escherichia coli. Infect Immun 69, 6863-6873.

Shin, R., Suzuki, M. \& Morishita, Y. (2002). Influence of intestinal anaerobes and organic acids on the growth of enterohaemorrhagic Escherichia coli O157:H7. J Med Microbiol 51, 201-206.

Srimanote, P. (2003). Analysis of putative virulence factors of a locus of enterocyte effacement-negative Shiga toxigenic Escherichia coli O113:H21 strain. PhD thesis, University of Adelaide, Australia.

Tarr, P. I., Neill, M. A., Clausen, C. R., Newland, J. W., Neill, R. J. \& Moseley, S. L. (1989). Genotypic variation in pathogenic Escherichia coli O157:H7 isolated from patients in Washington, 1984-1987. J Infect Dis 159, 344-347.

Tarr, P. I., Bilge, S. S., Vary, J. C., Jr, Jelacic, S., Habeeb, R. L., Ward, T. R., Baylor, M. R. \& Besser, T. E. (2000). Iha: a novel Escherichia coli O157:H7 adherence-conferring molecule encoded on a recently acquired chromosomal island of conserved structure. Infect Immun 68, 1400-1407.

Taylor, D. E., Rooker, M., Keelan, M., Ng, L. K., Martin, I., Perna, N. T., Burland, N. T. \& Blattner, F. R. (2002). Genomic variability of $O$ islands encoding tellurite resistance in enterohemorrhagic Escherichia coli O157:H7 isolates. J Bacteriol 184, 4690-4698.

Toma, C., Martinez Espinosa, E., Song, T., Miliwebsky, E., Chinen, I., lyoda, S., Iwanaga, M. \& Rivas, M. (2004). Distribution of putative adhesins in different seropathotypes of Shiga toxin-producing Escherichia coli. J Clin Microbiol 42, 4937-4946.

Touati, D. (2000). Iron and oxidative stress in bacteria. Arch Biochem Biophys 373, 1-6.

Yanisch-Perron, C., Vieira, J. \& Messing, J. (1985). Improved M13 phage cloning vectors and host strains: nucleotide sequences of the M13mp18 and pUC19 vectors. Gene 33, 103-119.

Edited by: V. Sperandio 